\title{
Functional dependences of the performance of a mixer with helical blades
}

\author{
Vladimir B. Novikov ${ }^{1}$, Vladimir V. Konovalov ${ }^{2}$, Alexander L. Mishanin ${ }^{1}$, Marina V. Borisova ${ }^{1, *}$, and Alexey S. Gretsov ${ }^{1}$ \\ ${ }^{1}$ Samara State Agricultural University, 446442 Kinel, Samara region, Russia \\ ${ }^{2}$ Penza State Technical University, 440039 Penza, Russia
}

\begin{abstract}
The level of livestock development is one of the indicators characterizing the state of economy not only of individual farms, but regions and state as a whole. Therefore, the solution to the problem of the improvement of the quality of feed and modernization of process of its production is relevant and significant for agricultural sector. In order to improve and study the technological process of mixing the grain mixture, a design of a continuous paddle mixing unit was developed. The purpose of the research is to establish functional dependencies on the design and operating parameters of a mixer with helical blades and determine their rational values. The influence of the shaft rotation frequency, the number of its blades and the state of tank fullness on the unevenness of the mixture, productivity and power consumption is determined. The increase in the degree of fullness and shaft speed intensifies the performance of the mixer. The highest mixer performance is provided by 6 blades. The increase in the shaft speed intensifies the power consumption of the mixer. The degree of fullness of the tank and the number of blades also increase power consumption, but to a lesser extent. The best quality of the mixture is provided by 8 blades with a degree of fullness of $25 \%$ and a rotation frequency of $40 \mathrm{~min}^{-1}$ with a mixer capacity of about $180 \mathrm{~kg} / \mathrm{h}$ and a power consumption of 270 watts.
\end{abstract}

\section{Introduction}

The production of animal feed is one of the main tasks for the increase in the productivity of animals. Feed mixtures prepared from several components of biologically active substances have a complete set of substances unlike other types of feed.

The production of high-quality animal feeds depends on the quality of mixing $[1,7]$. The production of feed mixtures is carried out mainly in mixers of various designs, which should provide the required uniformity with minimal specific energy costs [2-8].

\section{Material and methods}

In order to improve and study the technological process of mixing the grain mixture the design of a continuous paddle mixing unit of bulk materials was developed in Samara State Agrarian University. The mixing chamber of the proposed unit is shown in Figure 1.

In order to determine the quality of mixing, productivity and power consumption, depending on the design parameters of the mixer, a factorial experiment was conducted.

$\mathrm{X} 1$ is the degree of the discharge window opening of the mixer $(\mathrm{E}=25,50$ and $75 \%) ; \mathrm{X} 2$ - shaft rotation frequency $\left(\mathrm{n}=20,30\right.$ and $\left.40 \mathrm{~min}^{-1}\right) ; \mathrm{X} 3$ - the number of blades $(\mathrm{z}=4,6$ and $8 \mathrm{pcs}) ; \mathrm{v}$ - mixing unevenness, \%; $\mathrm{Q}_{\mathrm{dc}}-$ discharge capacity, $\mathrm{kg} / \mathrm{h} ; \mathrm{P}$ - power, W.

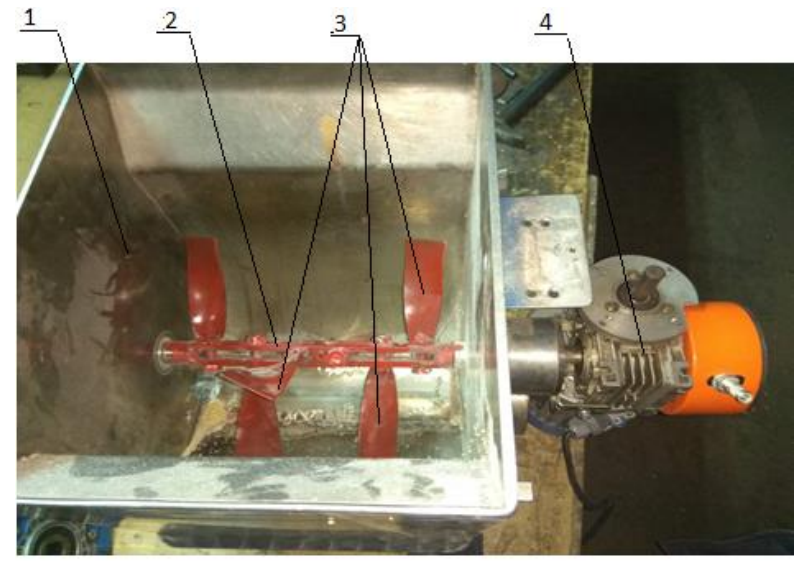

Fig.1. General view of mixing chamber: 1 - mixing chamber; 2 - shaft; 3 - helical blades; 4 - electric motor

\section{Results}

Table 1 presents the results of experiment.

In order to describe the mixing unevenness (\%), a quadratic model is used in the coded value of factors:

$$
\begin{gathered}
\nu=25.32+3.051961 \cdot \mathrm{X} 1-3.1069 \cdot \mathrm{X} 2-3.02741 \cdot \mathrm{X} 3+ \\
-0.15086 \cdot \mathrm{X} 1 \cdot \mathrm{X} 1+0.146552 \cdot \mathrm{X} 2 \cdot \mathrm{X} 2+1.049138 \cdot \mathrm{X} 3 \cdot \mathrm{X} 3+ \\
-0.0098 \cdot \mathrm{X} 1 \cdot \mathrm{X} 2+0.022549 \cdot \mathrm{X} 1 \cdot \mathrm{X} 3+0.733621 \cdot \mathrm{X} 2 \cdot \mathrm{X} 3 .(1)
\end{gathered}
$$

Correlation parameter - $\mathrm{R}=0.96024$ and $\mathrm{F}$ test $=0986528$ indicate the adequacy of the model.

\footnotetext{
*Corresponding author: morskay6363@mail.ru
} 
Mixing unevenness (\%) in the natural values of factors is presented as a power function (Fig. 2):

$$
v=-1922.1+105.3085 \cdot E^{0.0446}+418.16 \cdot \mathrm{n}^{-0.01834}+
$$

$1440.9 \cdot Z^{-0.0045}$.

Table 1. Mixer experiment results

\begin{tabular}{|c|c|c|c|c|c|c|c|c|c|c|c|c|c|}
\hline № & $\mathrm{X} 1$ & $\mathrm{X} 2$ & $\mathrm{X} 3$ & $\mathrm{E}, \%$ & $\begin{array}{c}\mathrm{n}, \\
\mathrm{min}^{-1}\end{array}$ & $\begin{array}{c}\mathrm{Z}, \\
\mathrm{pcs} .\end{array}$ & $\begin{array}{c}\mathrm{M}, \\
\mathrm{kg}\end{array}$ & $\mathrm{T}_{\mathrm{d}, \mathrm{c}}$ & $\begin{array}{c}\mathrm{Q}_{\mathrm{dc},} \\
\mathrm{kg} / \mathrm{h}\end{array}$ & $\mathrm{U}, \mathrm{B}$ & $\mathrm{I}, \mathrm{A}$ & $\mathrm{P}, \mathrm{W}$ & $\mathrm{v}, \%$ \\
\hline X.X. & & & & & 20 & & - & - & - & 101 & 0.7 & 70.7 & 27.7 \\
\hline X.X. & & & & & 25 & & - & - & - & 128 & 1 & 128.0 & 25.5 \\
\hline X.X. & & & & & 30 & & - & - & - & 145 & 1.2 & 174.0 & 21.6 \\
\hline X.X. & & & & & 35 & & - & - & - & 172 & 1.2 & 206.4 & 28.4 \\
\hline X.X. & & & & & 40 & & - & - & - & 191 & 1.4 & 267.4 & 23.4 \\
\hline 1 & 1 & 0 & 0 & 75 & 30 & 6 & 6.1 & 110 & 199.6 & 150 & 2.1 & 315.0 & 23.8 \\
\hline 2 & 0 & 0 & 0 & 50 & 30 & 6 & 4.0 & 90 & 160.0 & 147 & 1.6 & 235.2 & 17.7 \\
\hline 3 & -1 & 0 & 0 & 25 & 30 & 6 & 2.0 & 60 & 120.0 & 146 & 1.1 & 160.6 & 22.7 \\
\hline 4 & 0 & -1 & 0 & 50 & 20 & 6 & 4.0 & 100 & 144.0 & 102 & 0.9 & 91.8 & 28.9 \\
\hline 5 & 0 & 1 & 0 & 50 & 40 & 6 & 4.0 & 70 & 205.7 & 194 & 1.6 & 310.4 & 23.6 \\
\hline 6 & 1 & 1 & 1 & 75 & 40 & 8 & 6.1 & 65 & 337.8 & 194 & 2.1 & 407.4 & 28.1 \\
\hline 7 & -1 & 1 & 1 & 25 & 40 & 8 & 2.0 & 40 & 180.0 & 191 & 1.5 & 286.5 & 28.3 \\
\hline 8 & -1 & -1 & 1 & 25 & 20 & 8 & 2.0 & 70 & 102.8 & 190 & 0.8 & 152.0 & 33.2 \\
\hline 9 & 1 & -1 & 1 & 75 & 20 & 8 & 6.1 & 95 & 231.2 & 104 & 1.1 & 114.4 & 22.2 \\
\hline 10 & 0 & 0 & 1 & 50 & 30 & 8 & 4.0 & 55 & 261.8 & 149 & 1.2 & 178.8 & 27.2 \\
\hline 11 & 0 & 0 & -1 & 50 & 30 & 4 & 4.0 & 70 & 205.7 & 146 & 1.3 & 189.8 & 27.7 \\
\hline 12 & 1 & 1 & -1 & 75 & 40 & 4 & 6.1 & 55 & 399.2 & 196 & 1.7 & 333.2 & 25.5 \\
\hline 13 & 1 & 0 & -1 & 75 & 20 & 4 & 6.1 & 100 & 219.6 & 104 & 1.1 & 114.4 & 21.6 \\
\hline 14 & -1 & 1 & -1 & 25 & 40 & 4 & 2.0 & 45 & 160.0 & 191 & 1.3 & 248.3 & 28.4 \\
\hline 15 & -1 & 0 & -1 & 25 & 20 & 4 & 2.0 & 70 & 102.8 & 102 & 0.9 & 91.8 & 23.4 \\
\hline
\end{tabular}

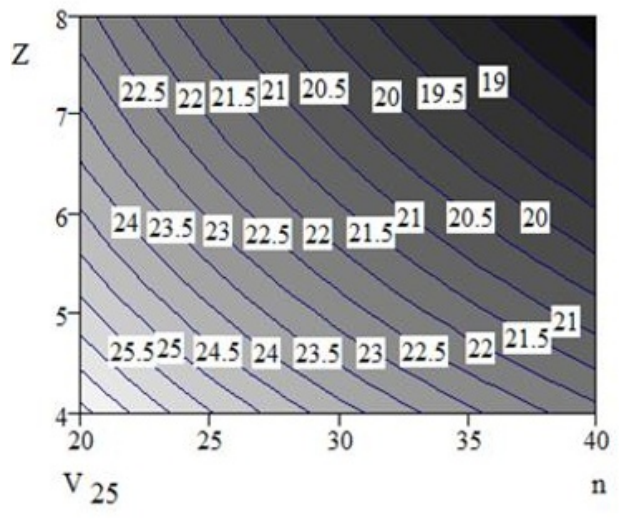

(a)

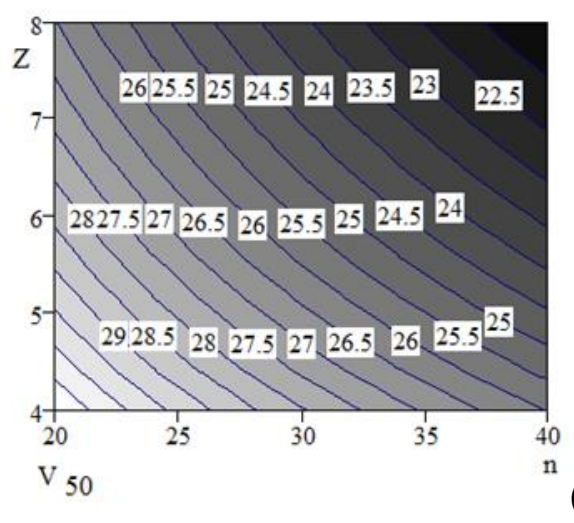

(b)
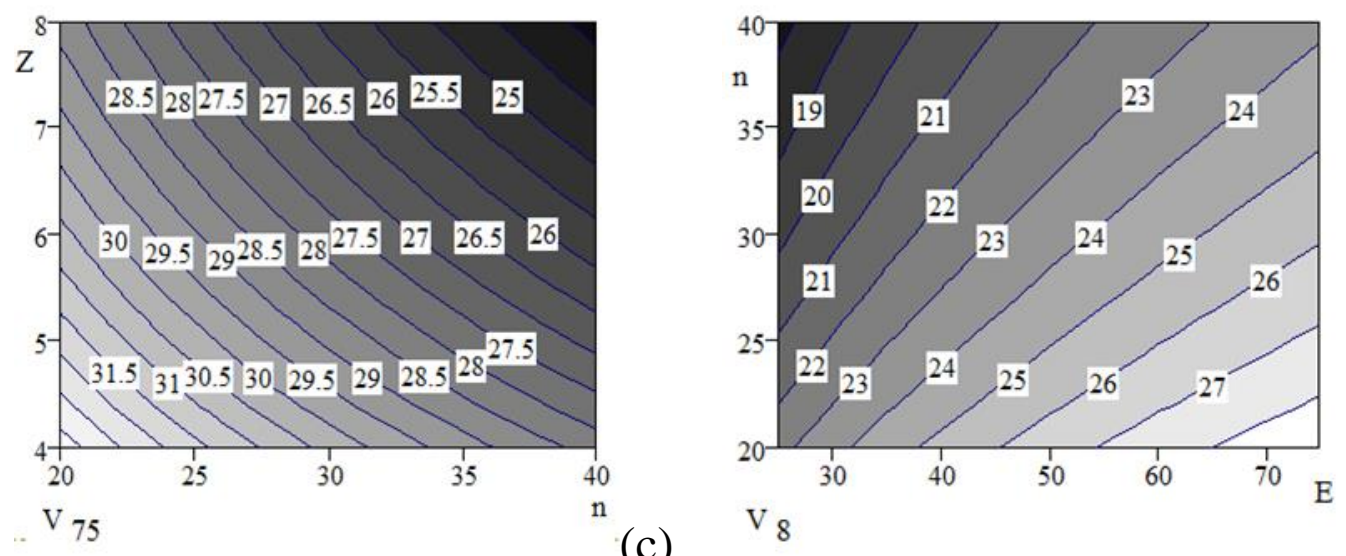

(c)

Fig. 2. Two-dimensional sections of the mixture unevenness $v(\%)$ of the natural values of the factors: (a), (b), (c) - rotation speed $n$ $\left(\mathrm{min}^{-1}\right)$ and the number of blades $\mathrm{z}$ (pcs.) with a tank fullness degree of $25,50,75 \%$; (d) - the degree of tank fullness $\mathrm{E}(\%)$ and the rotational speed equal to $\mathrm{n}\left(\mathrm{min}^{-1}\right)$ with the number of blades equal to $\mathrm{z}=8$ pcs. 


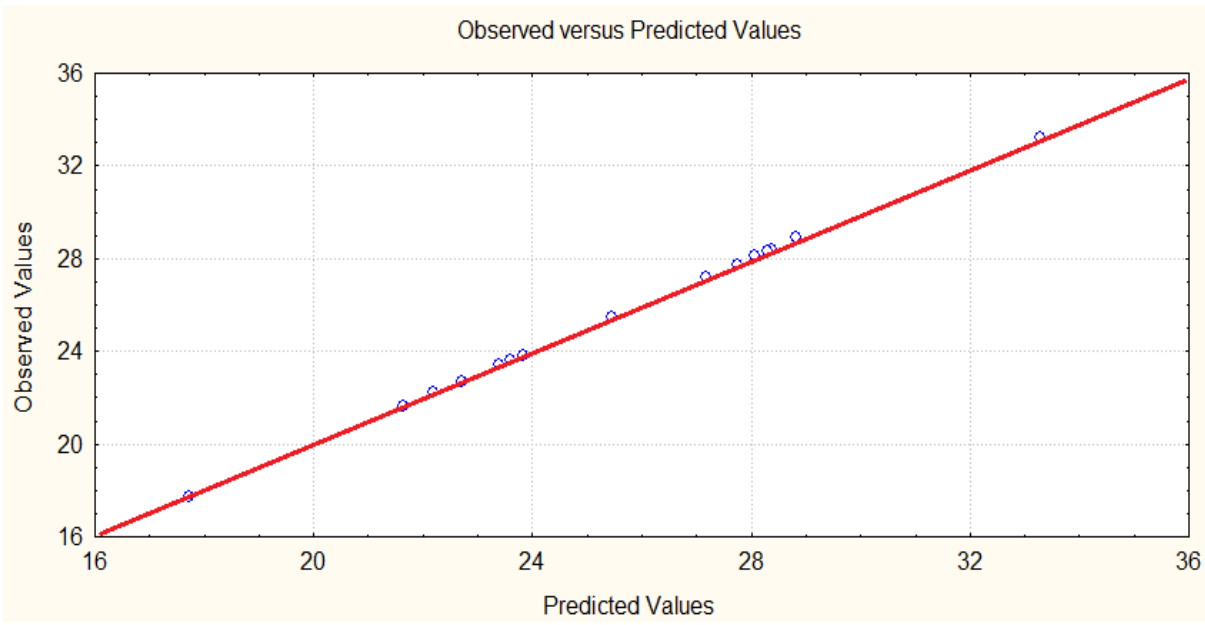

Fig. 3. Results of the convergence verification of the predicted and observed values of the mixture unevenness $v, \%$

Correlation parameter $-\mathrm{R}=0.999946$ and F-test $=0.999766$ indicate the adequacy of the model (Fig. 3) and the possibility of its use.

The least unevenness of the mixture is observed when the degree of tank fullness is $25 \%$ and the speed of rotation is $40 \mathrm{~min}^{-1}$ with 8 blades. The increase in the number of impacts of the blades improves the quality of the mixture.

In order to describe the mixer performance $(\mathrm{kg} / \mathrm{h}), \mathrm{a}$ quadratic model for natural values was used (Fig. 4):

$$
\begin{aligned}
& \mathrm{Q}_{\mathrm{V}}=362.9054+3.940444 \cdot E+2.559039 \times \\
& \quad \times \mathrm{n}-158.995 \cdot \mathrm{Z}-0.02286 \cdot E \cdot E+ \\
& \quad+0.007494 \cdot \mathrm{n} \cdot \mathrm{n}+14.9146 \cdot \mathrm{Z} \cdot \mathrm{Z}+ \\
& \quad+0.076037 \cdot E \cdot \mathrm{n}-0.17467 \cdot E \cdot \mathrm{Z}+ \\
& \quad+-0.33116 \cdot \mathrm{n} \cdot \mathrm{Z} . \\
& \text { Correlation parameter } \quad-\quad \mathrm{R}=0.96687 \quad \text { and }
\end{aligned}
$$

F-test $=0.901448$ indicate the adequacy of the model.
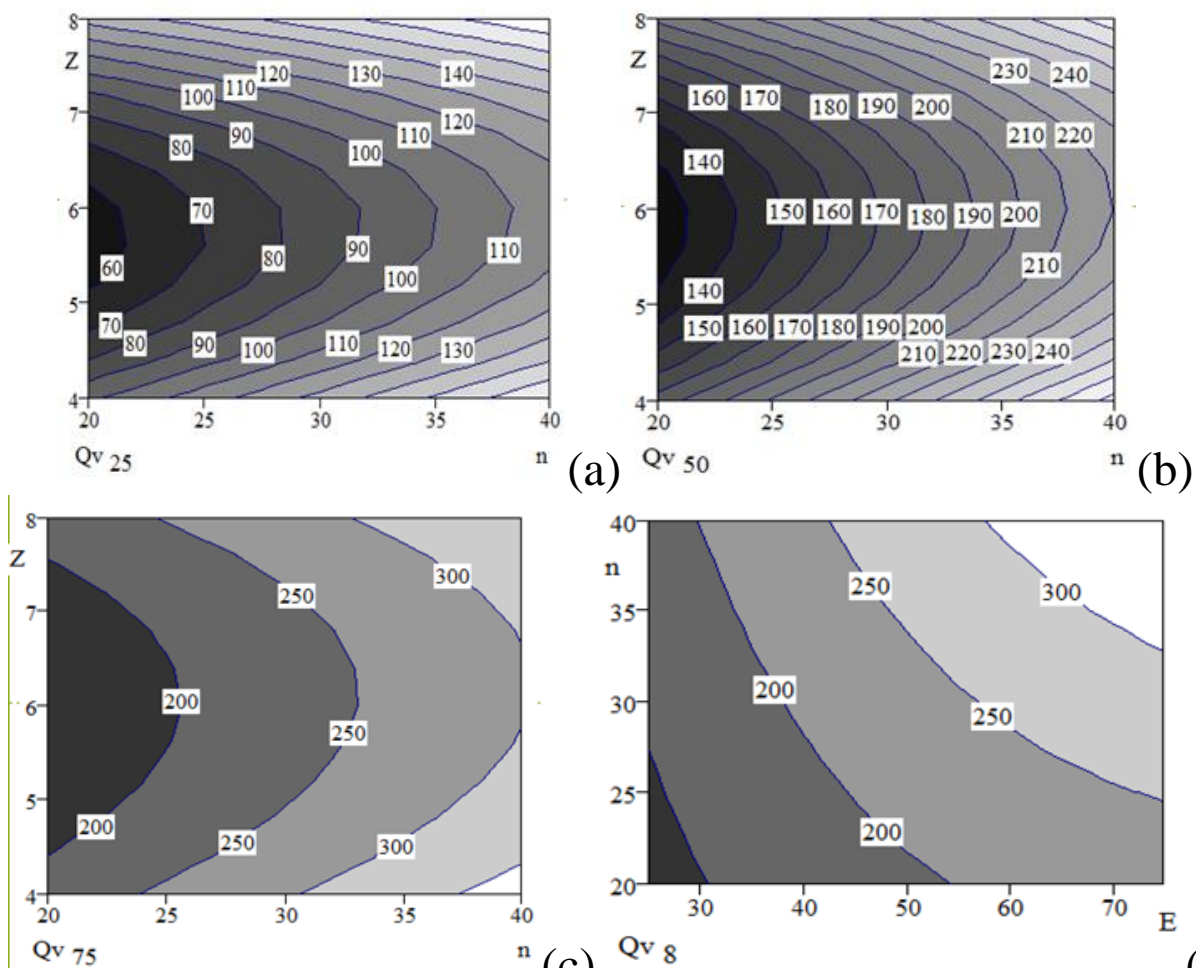

(a)

(b)

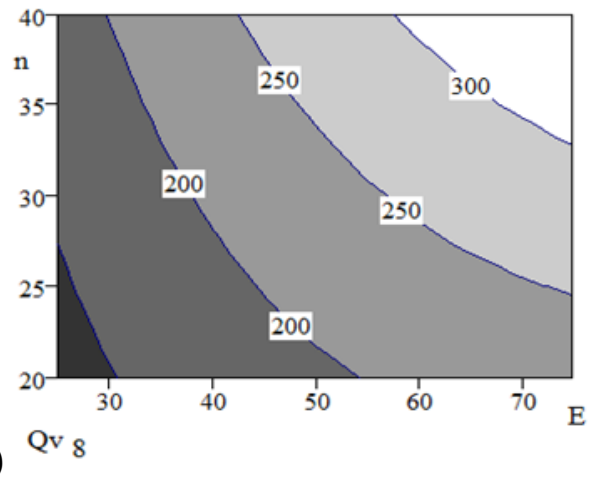

(d)

Fig. 4. Two-dimensional sections of productivity $\mathrm{Q}(\mathrm{kg} / \mathrm{h})$ of the natural values of factors: (a), (b), (c) - rotation speed $\mathrm{n}\left(\mathrm{min}^{-1}\right)$ and the number of blades $\mathrm{z}$ (pcs.) with tank fullness degree of $25,50,75 \%$; (d) - tank fullness degree $\mathrm{E}(\%)$ and the rotation speed equal to $\mathrm{n}\left(\mathrm{min}^{-1}\right)$ with the number of blades equal to $\mathrm{z}=8$ pcs.

The increase in the degree of fullness and shaft speed increases the performance of the mixer. The highest mixer performance is provided by 6 blades. The best quality of the mixture is provided by 8 blades with a degree of fullness equal to $25 \%$ and rotation frequency of $40 \mathrm{~min}^{-1}$ with a mixer capacity of about $180 \mathrm{~kg} / \mathrm{h}$.

In order to describe the power on the mixer drive $(\mathrm{kg} / \mathrm{h})$, a power-law model for natural values was used (Fig. 4): 


$$
\begin{aligned}
& P=21.7+\left(0.57023 \cdot E^{0.353387}\right) \cdot \times \\
& \times\left(0.2366 \cdot n^{1.653896}\right) \cdot\left(0.839 \cdot Z^{0.237452}\right) .
\end{aligned}
$$

Correlation parameter $-\mathrm{R}=0.95185$ and F-test $=0.9056094$ indicate the adequacy of the model.

Comparing the obtained observed and predicted values, the correlation parameter is determined: $\mathrm{R}=0.97102$. The value of F-test $=0.91393$ indicates a confidence probability of the compliance with the samples of more than $90 \%$, which indicates the adequacy of the model and the possibility of its use. The

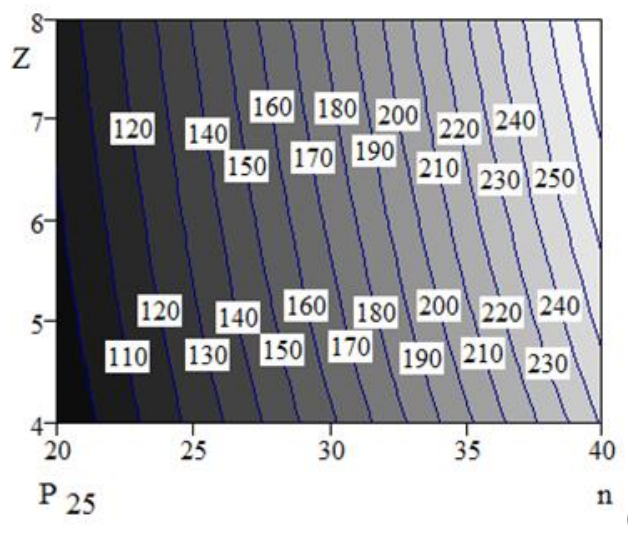

(a)

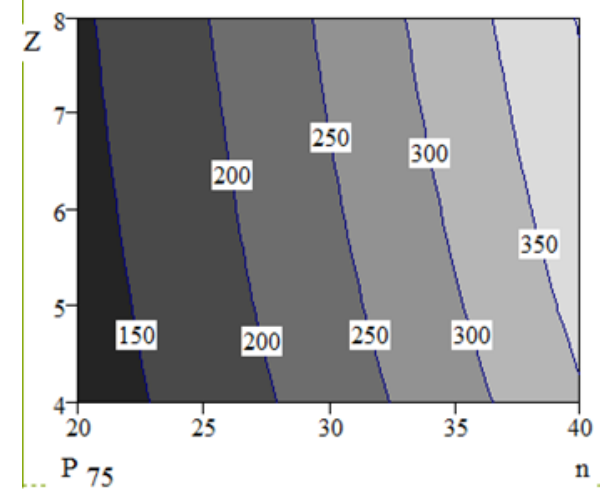

${ }^{\mathrm{n}}$ (c) correspondence of the observed and predicted values is presented in Figure 6.

The increase of the shaft speed increases the power consumption of the mixer. The degree of tank fullness and the number of blades also increase power consumption, but to a lesser extent. The best quality of the mixture is provided by 8 blades with a degree of fullness of $25 \%$ and a rotation frequency of $40 \mathrm{~min}^{-1}$ with a mixer capacity of about $180 \mathrm{k} / \mathrm{h}$ and a power consumption of 270 watts.

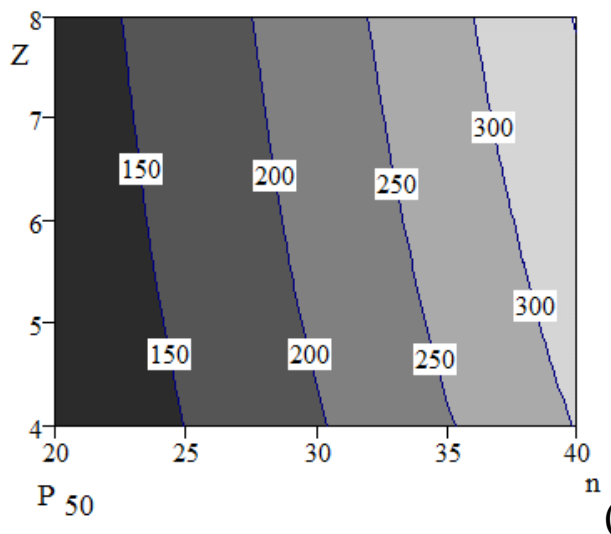

(b)

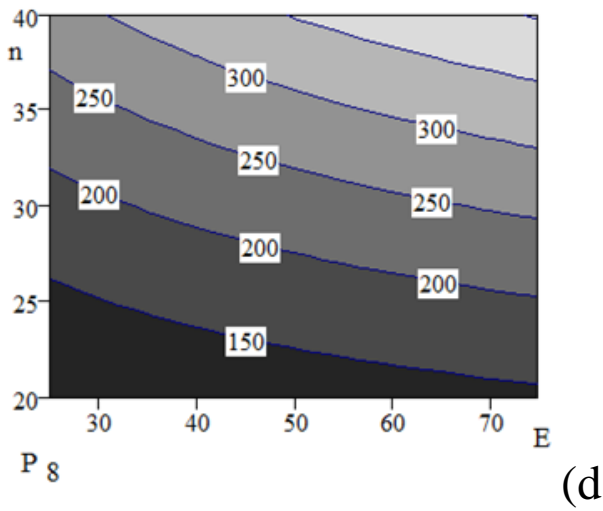

Fig. 5. Two-dimensional sections of Power (W) of the drive unit of the mixer: (a), (b), (c) - rotation speed $\mathrm{n}\left(\mathrm{min}^{-1}\right)$ and the number of blades $\mathrm{z}$ (pcs.) with tank fullness degree of 25, 50, $75 \%$; (d) - tank fullness degree $\mathrm{E}(\%)$ and the rotation speed equal to $\mathrm{n}\left(\mathrm{min}^{-1}\right)$ with the number of blades equal to $\mathrm{z}=8$ pcs.

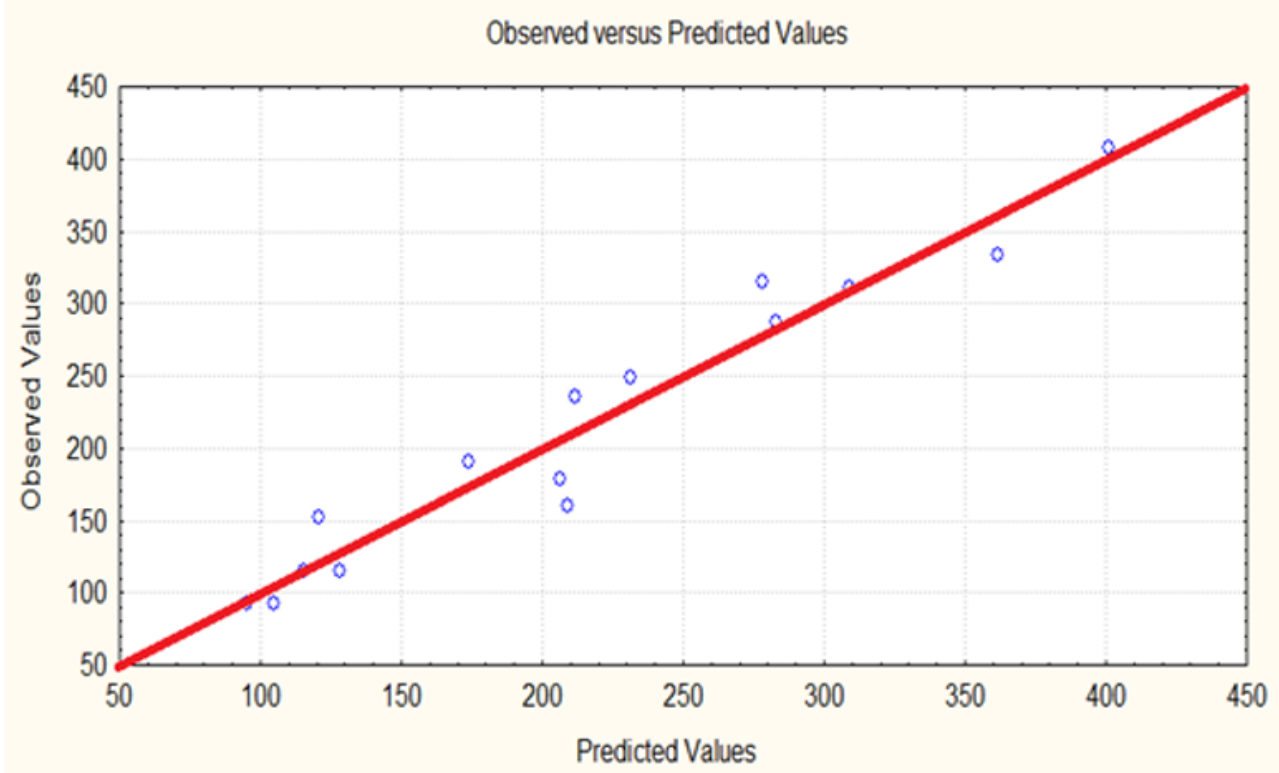

Fig. 6. Results of the convergence verification of the predicted and observed values of power, W 
Analysis of the quality of the mixture relative to the mass of the mixture $\mathrm{Mk}$, attributable to the impact of the blade $(\mathrm{kg} / \mathrm{pc})$, allowed us to establish the dependence of the mixing unevenness (\%) with the correlation coefficient of the results $\mathrm{R}=0.99369$ and F-test $=0.98141$,

$$
v=-192.286+253.6435 \cdot(\mathrm{Mk})^{0.028089}
$$

From this expression, we can express the function of the calculated value of the mass of the mixture per one impact of the blade:

$$
\mathrm{Mk}=(0.7581+0.00394 \cdot v)^{(1000000 / 28089)}
$$

The mass of the mixture attributable to the impact of the blade is initially determined, $\mathrm{kg} / \mathrm{pc}$ :

$$
M k=\frac{(V \cdot \varepsilon \cdot \rho)}{(n \cdot Z \cdot T)}
$$

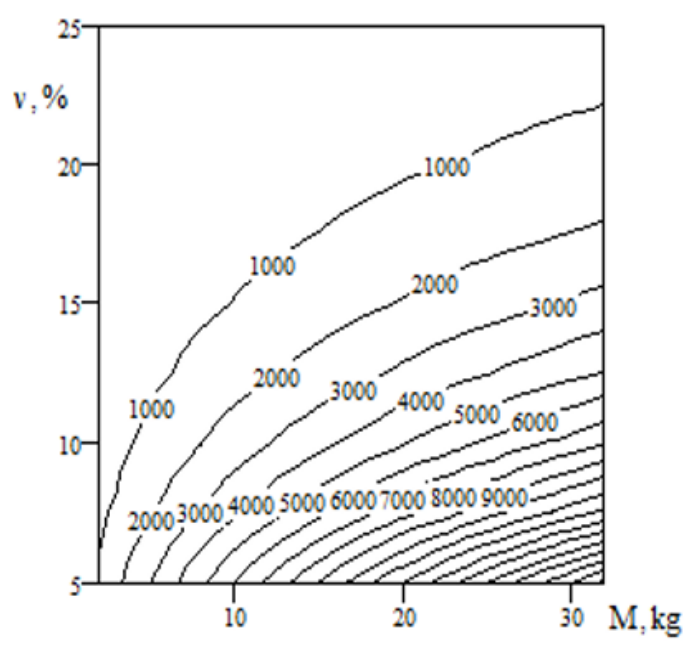

T
The results presented allow us to analyze the operation of the mixer based on simulation. From expressions (6) and (7) we express the mixing time $\mathrm{T}$, as well as determine the performance of the mixer on mixing: $\mathrm{Qcm}=\mathrm{M} / \mathrm{T}(\mathrm{kg} / \mathrm{s})$. Let us simulate the operation of the mixer based on the variable mass value of the prepared portion of the mixture and the required value of the mixture unevenness $v$ (coefficient of variation of the control component).

An increase in portion weight requires an increase in mixing time (Fig. 7.a). Reducing the unevenness of the mixture also requires an increase in the duration of mixing. The most intensive increase in mixing time with unevenness of less than $10 \%$. This significantly reduces the mixing performance of the mixer. Furthermore, performance practically does not depend on the mass of the prepared portion.

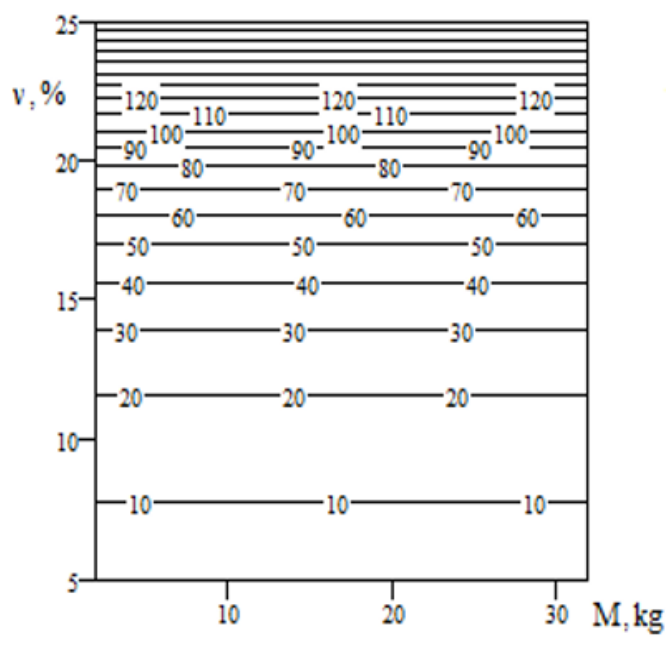

$3600 \cdot Q \mathrm{~cm}$ (b)

Fig. 7. The simulation results of the effect of the mass of the prepared portion of the mixture $\mathrm{M}(\mathrm{kg})$ and the unevenness of the mixture $v(\%)$ on: the required mixing time $\mathrm{T}(\mathrm{sec})$ and continuous mixing productivity of $3600 \mathrm{Qcm}(\mathrm{kg} / \mathrm{h})$ with a constant degree of filling of the mixer $-20 \%$.

\section{Conclusion}

The increase in the degree of fullness and shaft speed increases the performance of the mixer. The highest mixer performance is provided by 6 blades. The increase of the shaft speed increases the power consumption of the mixer. The degree of tank fullness and the number of blades also increase power consumption, but to a lesser extent. The best quality of the mixture is provided by 8 blades with a degree of fullness equal to $25 \%$ and a rotation frequency of $40 \mathrm{~min}^{-1}$ with the mixer capacity of about $180 \mathrm{~kg} / \mathrm{h}$ and a power consumption of 270 watts.

The duration of mixing and productivity in the continuous mode in the event of a change in the mass of the prepared portion while ensuring a constant degree of filling the mixer container and its structural and kinematic parameters is mainly affected by the required unevenness of the mixture. When improving the unevenness of the mixture from the original $20 \%$ to the desired $10 \%$, the productivity decreases 5.7 times, if up to $5 \%$ - then 13.7 times.

\section{References}

1. M.V. Borisova, V.V. Novikov, V.V. Konovalov, Analytical justification of the performance of a mixer of bulk materials with helical blades, Bull. of the Samara State Agricult. Univer., 1, 69-78 (2019)

2. V.F. Pershin, Y.T. Selivanov, A.V. Orlov, Use of numerical experiments for optimization of mixing of granular materials, Theoret. Foundat. of Chem. Engineer., 38(2), 195-200 (2004)

3. M.V. Fomina, Justification of the parameters of narrow flat blades of a high-speed mixer of loose components, Innovat. technique and technol., 4(05), 30-33 (2015) 
4. Y.T. Selivanov, V.F. Pershin, Experimental study of the mixing of disperse materials with different particle sizes, Theoret. Foundat. of Chem. Engineer., 35(2), 206-208 (2001)

5. S. Soni et al., Compact coiled flow inverter for process intensification, Chem.1 Engineer. Sci., 193, 312-324 (2019)

6. A. Chupshev, V. Konovalov, M. Fomina, Optimization in work modeling of a mixer, J. of
Phys.: Conf. Ser., IOP Publish., 1084(1), 012010 (2018)

7. S.M. Vedischev, A.V. Prokhorov, N.V. Kolshev, Mixer of dry feed mixtures, Issues of modern sci. and pract. Univer. named after Vernadsky, 4(42), 326-328 (2012)

8. V.F. Pershin, Y.T. Selivanov, Calculations on a drum mixer with ordered loading, Chem. and petrol. Engineer., 38(1), 53-57 (2002) 